\title{
Tofacitinib in the management of active psoriatic arthritis: patient selection and perspectives
}

This article was published in the following Dove Press journal:

Psoriasis: Targets and Therapy

\author{
Karen Ly (iD) \\ Kristen M Beck (iD) \\ Mary P Smith (D) \\ Ana-Maria Orbai iD ${ }^{2}$ \\ Wilson Liao (D) \\ 'Department of Dermatology, University \\ of California San Francisco, San Francisco, \\ CA, USA; ${ }^{2}$ Division of Rheumatology, \\ Johns Hopkins University, Baltimore, \\ MD, USA
}

\begin{abstract}
Tofacitinib is an oral Janus kinase inhibitor approved for the treatment of psoriatic arthritis (PsA). It provides an alternative option for patients who have had an inadequate response and tolerance to other disease modifying antirheumatic drugs (DMARDs). It has demonstrated comparable efficacy to biologics, is effective in the management of treatment resistant disease, and is reported to improve enthesitis, dactylitis, and radiographic progression. Tofacitinib is also associated with an increased risk of serious infections, malignancy, and laboratory abnormalities. There is currently a large armamentarium of therapies for psoriatic arthritis, and choosing among treatments can be challenging. Due to this wide selection, a thorough assessment of psoriatic disease phenotype, patient preference, disease presentation, and comorbidities is critical. This review addresses key considerations in patient selection for the treatment of PsA with tofacitinib.
\end{abstract}

Keywords: tofacitinib, psoriatic arthritis, janus kinase, kinase inhibitors

\section{Introduction}

Psoriatic arthritis (PsA) is a chronic, inflammatory musculoskeletal disease that is characterized by peripheral arthritis, enthesitis, dactylitis, and spondylitis with or without nail and skin lesions. ${ }^{1,2}$ It is a systemic disease that develops in up to $40 \%$ of psoriasis patients in their lifetime ${ }^{3-5}$ with manifestations that include pain, swelling, stiffness, and entheses of the peripheral joints and/or axial skeleton. Dactylitis, fusiform full thickness swelling of fingers or toes, can develop in about half of individuals with PsA. In addition, it is also associated with significant comorbidities such as diabetes mellitus, depression, hypertension, cardiovascular disease, and decreased quality of life. ${ }^{1,5}$ Although the pathogenesis of PsA has not been fully elucidated, it likely results from a combination of genetic, environmental, and immunologic factors. ${ }^{6}$

PsA is a heterogeneous disease with diverse clinical presentations, making early diagnosis and management challenging. ${ }^{7}$ There are five distinct clinical subtypes: the oligoarticular subtype affects four or fewer joints in an asymmetric distribution; the polyarticular subtype affects at least five joints, is symmetrical, and most similar to rheumatoid arthritis; the distal subtype involves the distal interphalangeal joints of the hands and feet; the arthritis mutilans subtype is the most severe and characterized by bone resorption or osteolysis that results in significant deformities; and the spondyloarthritis subtype, which primarily affects the spine and sacroiliac joints. ${ }^{8}$ Effective treatment of this rheumatologic disease is critical to minimize damage, ${ }^{9}$ negative impact on quality of life and to mitigate the risk of comorbid disease.
Department of Dermatology, University of California San Francisco, 515 Spruce Street, San Francisco, CA 94118, USA

$\mathrm{Tel}+$ I 415476470 I

Fax +I 4I5 5024126

Email kristenbeckmd@gmail.com 
Current PsA treatment guidelines include nonsteroidal anti-inflammatory drugs, glucocorticoids, oral small molecules (methotrexate, sulfasalazine, cyclosporine, leflunomide, apremilast), tumor necrosis factor alpha (TNF- $\alpha$ ) inhibitors (etanercept, adalimumab, infliximab, golimumab, certolizumab), interleukin (IL) 12/23 inhibitors (ustekinumab), IL-17 inhibitors (secukinumab, ixekizumab), CTLA4-Ig (abatacept), and the janus kinase inhibitor (tofacitinib). ${ }^{10-12}$ Each therapy has a distinct safety and efficacy profile, and treatment plans should be individualized and optimized by taking into account clinical presentation and medical history. While there are many treatment options for the management of PsA, it can be challenging for practitioners to select among therapies. This review addresses key considerations in patient selection for the treatment of psoriatic arthritis with tofacitinib.

\section{Practical considerations}

Tofacitinib (Xeljanz, Pfizer Inc.) is an orally administered inhibitor of predominantly JAK1 and JAK3, with functional selectivity over JAK2. ${ }^{4,13,14}$ Blockade of the JAK receptor downregulates the production of cytokines important in the pathogenesis of PsA, including TNF- $\alpha$, IL-17, IL-6, IL-23. ${ }^{14,15}$ Tofacitinib is currently approved for the treatment of PsA, rheumatoid arthritis, and ulcerative colitis. $^{16}$

Tofacitinib is indicated for patients with active PsA who have had a poor response or intolerance to methotrexate or other disease modifying antirheumatic drugs (DMARDs). Since tofacitinib has not been evaluated as a monotherapy in PsA, it is recommended that it be used in combination with a conventional synthetic DMARDs (csDMARD), such as methotrexate, sulfasalazine, and leflunomide. Tofacitinib should not be used in combination with biologic DMARDs or potent immunosuppressants, such as cyclosporine and azathioprine due to risk of added immunosuppression.

Tofacitinib is available as a 5 milligram $(\mathrm{mg})$ or $10 \mathrm{mg}$ immediate release tablet and as an $11 \mathrm{mg}$ extended release tablet. The recommended dosing for both PsA and rheumatoid arthritis is immediate release $5 \mathrm{mg}$ twice daily or extended release $11 \mathrm{mg}$ once daily in combination with non-biologic DMARDs. For ulcerative colitis, the recommended dose is $10 \mathrm{mg}$ twice daily for 8 weeks; followed by 5 or $10 \mathrm{mg}$ twice daily, depending on the patient's response. Dose adjustments are recommend for patients concomitantly taking medications that undergo CYP3A4 inhibition as tofacitinib is primarily metabolized by this pathway. ${ }^{16}$

Tofacitinib has no contraindications, but there are FDA-required black box warnings for an increased risk of serious infections and malignancies. ${ }^{16}$ Patients should be evaluated for latent or active tuberculosis infection prior to treatment with tofacitinib, and anti-tuberculosis therapy should occur prior to initiating this medication. Due to the increased risk of serious infections, the risks and benefits of therapy should be weighed in patients with a history of chronic or recurrent infections. Additionally, lymphomas and other malignancies have been observed in patients treated with tofacitinib and an increased risk of EBV-associated post-transplant lymphoproliferative disease was observed in renal transplant patients.

In February 2019, the FDA reported a safety alert regarding the increased risk of pulmonary embolism and death for the $10 \mathrm{mg}$ twice daily dose of tofacitinib, which was noted during a safety trial in patients with rheumatoid arthritis. ${ }^{17}$ For this reason, patients taking the $10 \mathrm{mg}$ twice daily dose were decreased to a dose of $5 \mathrm{mg}$ twice daily. Further data is needed to elucidate this risk, and the safety trial is anticipated to be completed by the end of 2019 . Tofacitinib $10 \mathrm{mg}$ twice daily is not an approved dose for the treatment of PsA. No data has been provided on the risk of tofacitinib $11 \mathrm{mg}$ extended release.

Laboratory monitoring is required due to potential changes in lymphocytes, neutrophils, hemoglobin, liver enzymes, and lipids. Absolute lymphocyte counts (ALC) should be monitored at baseline and every three months thereafter. Absolute neutrophil counts (ANC) should be measured at baseline, after four to eight weeks of treatment, and every three months thereafter. Hemoglobin is monitored at baseline, after four to eight weeks of treatment, and every three months thereafter. Liver function tests (LFTs) should be routinely monitored, and lipids should be assessed four to eight weeks following initiation of therapy.

\section{Psoriatic arthritis clinical trials}

Two phase III randomized controlled trials (RCTs) evaluated the efficacy and safety of tofacitinib in PsA: OPAL Broaden ${ }^{11}$ and OPAL Beyond. ${ }^{12}$ In both studies, the co-primary endpoints were the proportion of patients with a $20 \%$ improvement of the American College of Rheumatology criteria (ACR20) at three months and the change from baseline in the Health Assessment Questionnaire-Disability Index (HAQ-DI) at three months. The co-primary efficacy endpoints were achieved in both RCTs (Table 1). 
Table I Summary of key Phase III clinical trial results of tofacitinib for the treatment of psoriatic arthritis at month three

\begin{tabular}{|c|c|c|c|c|c|c|c|}
\hline \multirow[t]{2}{*}{ Endpoints } & \multicolumn{4}{|c|}{ OPAL Broaden } & \multicolumn{3}{|c|}{ Opal Beyond } \\
\hline & $\begin{array}{l}\text { Placebo } \\
(n=105)\end{array}$ & $\begin{array}{l}\text { Tofacitinib } \\
5 \mathrm{mg}(\mathrm{n}-107)\end{array}$ & $\begin{array}{l}\text { Tofacitinib } \\
10 \mathrm{mg} \\
(\mathrm{n}=104)\end{array}$ & $\begin{array}{l}\text { Adalimumab } \\
40 \mathrm{mg} \mathrm{Q2W} \\
(\mathrm{n}=106)\end{array}$ & $\begin{array}{l}\text { Placebo } \\
(n=|3|)\end{array}$ & $\begin{array}{l}\text { Tofacitinib } \\
5 \mathrm{mg} \\
(\mathrm{n}=|3|)\end{array}$ & $\begin{array}{l}\text { Tofacitinib } \\
10 \mathrm{mg} \\
(\mathrm{n}=132)\end{array}$ \\
\hline $\begin{array}{l}\text { Primary Endpoints } \\
\qquad \text { ACR20 } \\
\Delta \text { HAQ-DI }\end{array}$ & $\begin{array}{l}33 \% \\
-0.18\end{array}$ & $\begin{array}{l}50 \% \\
-0.35\end{array}$ & $\begin{array}{l}61 \% \\
-0.40\end{array}$ & $\begin{array}{l}52 \% \\
-0.38\end{array}$ & $\begin{array}{l}24 \% \\
-0.14\end{array}$ & $\begin{array}{l}50 \% \\
-0.39\end{array}$ & $\begin{array}{l}47 \% \\
-0.35\end{array}$ \\
\hline $\begin{array}{l}\text { Secondary Endpoints } \\
\text { PASI75 } \\
\text { ACR50 } \\
\text { ACR70 } \\
\Delta \text { LEI } \\
\Delta \text { DSS } \\
\Delta \text { SF-36 } \\
\text { SFACIT-F }\end{array}$ & $\begin{array}{l}15 \% \\
10 \% \\
5 \% \\
-0.4 \\
-2.0 \\
2.1 \\
3.3\end{array}$ & $\begin{array}{l}43 \% \\
28 \% \\
17 \% \\
-0.8 \\
-3.5 \\
5.2 \\
7.0\end{array}$ & $\begin{array}{l}44 \% \\
40 \% \\
14 \% \\
-1.5 \\
-5.5 \\
5.2 \\
6.0\end{array}$ & $\begin{array}{l}39 \% \\
33 \% \\
19 \% \\
-1.1 \\
-4.0 \\
5.2 \\
6.0\end{array}$ & $\begin{array}{l}14 \% \\
15 \% \\
10 \% \\
-0.5 \\
-1.9 \\
1.7 \\
3.0\end{array}$ & $\begin{array}{l}21 \% \\
30 \% \\
17 \% \\
-1.3 \\
-5.2 \\
5.0 \\
7.0\end{array}$ & $\begin{array}{l}43 \% \\
28 \% \\
14 \% \\
-1.3 \\
-5.4 \\
4.1 \\
5.8\end{array}$ \\
\hline
\end{tabular}

Notes: All endpoints tested at three months; ACR20/50/70: a minimum of 20, 50, and 70\% improvement in the ACR response; PASI75: at least a $75 \%$ improvement in the PASI score; $\triangle \mathrm{HAQ-DI/LEI/DSS/SF-36/FACIT-F:} \mathrm{change} \mathrm{from} \mathrm{baseline} \mathrm{score.}$

Abbreviations: ACR, American College of Rheumatology; DSS, Dactylitis Severity Score; HAQ-DI, Health Assessment Questionnaire Disability Index; FACIT-F, Functional Assessment of Chronic Illness Therapy-Fatigue; LEl, Leeds Enthesitis Index; PASI, Psoriasis Area-and-Severity Index; SF-36, Study 36-Medical Outcomes Study 36-Item Short Form Health Survey.

OPAL Broaden was a 12-month double-blind, activecontrolled and placebo-controlled, phase 3 trial investigating the efficacy of tofacitinib compared to placebo or adalimumab in patients with active PsA with an inadequate response to csDMARDs. Inclusion criteria required TNF- $\alpha$ inhibitor naivety. Patients were randomly assigned to receive either tofacitinib $5 \mathrm{mg}$ or $10 \mathrm{mg}$ twice daily, adalimumab $40 \mathrm{mg}$ subcutaneously every two weeks, or placebo with a blinded switch to either $5 \mathrm{mg}$ or $10 \mathrm{mg}$ at three months. Patients were also required to receive a stable dose of csDMARD throughout the trial. This study was completed by 373 patients. With regards to the co-primary endpoints, a significantly greater proportion of patients at month three achieved ACR2 20 on tofacitinib (5 mg: 50\%, $p=0.01 ; 10 \mathrm{mg}: 61 \%, p<0.001$ ) compared to placebo (33\%); for reference, ACR20 in the adalimumab arm was $52 \%$. Tofacitinib was superior to placebo with respect to the mean change from baseline HAQ-DI score (5 mg: $-0.35, p=0.006 ; 10 \mathrm{mg}:-0.40, p<0.001)$ versus placebo $(-0.18)$; for reference mean HAQ-DI change with adalimumab was -0.38 .

Secondary endpoints of ACR50 (5 mg: $28 \%, p<0.001$; $10 \mathrm{mg}$ : 40, $p<0.001$; placebo: $10 \%$ ), ACR70 (5 mg: $17 \%$, $p=0.004 ; 10 \mathrm{mg}: 14 \%, p=0.02$; placebo: $5 \%$ ), and an improvement in the Psoriasis Area and Severity Index (PASI) of at least 75\% (PASI75; $5 \mathrm{mg}: 43 \%, p<0.001$; $10 \mathrm{mg}$ : 44\%, $p<0.001$; placebo: $15 \%$ ) were assessed and both doses of tofacitinib were found to be superior to placebo. The change in the Leeds Enthesitis Index (LEI) was found to be superior to placebo with tofacitinib $10 \mathrm{mg}$ $(-1.5$ versus $-0.4, p<0.001)$ but not with the tofacitinib $5 \mathrm{mg}$ dose $(-0.8$ versus -0.4$)$. Additional pre-specified secondary endpoints of Dactylitis Severity Score (DSS), Medical Outcomes Study 36-Item Short Form Health Survey (SF36), and the Functional Assessment of Chronic Illness Therapy-Fatigue (FACIT-F) were in the same direction as the primary endpoints but could not be assessed for significance due to hierarchical statistical testing of secondary endpoints. ${ }^{11,18}$ Radiographs of the hands and feet were assessed at baseline and 12 months using the van der Heijde-modified Total Sharp Score (mTSS). At 12 months, $91-98 \%$ of patients across all treatment groups met the radiographic criteria for nonprogression of joint damage, defined as a change in $\operatorname{mTSS}$ of $\leq 0.5, \leq 0$, or $\leq 0.66$ from baseline. ${ }^{11,19}$

In OPAL Broaden, adverse events (AEs) occurred more frequently with tofacitinib and adalimumab than placebo at three months (5 mg: $39 \%, 10 \mathrm{mg}$ : $45 \%$, adalimumab: $46 \%$, placebo: $35 \%$ ). The most common adverse events were nasopharyngitis, upper respiratory tract infection, and headache. Serious adverse events (SAEs) occurred more frequently with tofacitinib $5 \mathrm{mg}$ at three months (5 mg: $3 \%, 10 \mathrm{mg}: 1 \%$, adalimumab: $1 \%$, placebo: 1\%). At 12 months, three tofacitinib patients reported serious infections (influenza, appendicitis, and pneumonia) compared to one adalimumab patient (herpes simplex and 
streptococcal pyoderma). Herpes zoster occurred in four patients, all whom were treated with tofacitinib. Four cancers (bladder transitional cell carcinoma, squamous cell carcinoma of the vulva, invasive ductal breast carcinoma, and basal cell cancer) were reported, all in patients who received tofacitinib. One death due to cardiac arrest was reported in a patient treated with tofacitinib $5 \mathrm{mg}$.

At three months, neutrophil counts were more reduced in the active treatment groups than placebo. Elevations in alanine aminotransferase (ALT) and aspartate aminotransferase (AST) three or more times the upper limit of normal was observed in tofacitinib and adalimumab groups.

OPAL Beyond was a six-month RCT evaluating tofacitinib compared to placebo in patients with active PsA who had an inadequate response to TNF- $\alpha$ inhibitors. This study was completed by 345 patients. Similar to the results found in OPAL Broad, a significantly greater proportion of patients at month three achieved ACR2 0 on tofacitinib (5 mg: 50\%, $p<0.001 ; 10 \mathrm{mg}: 47 \%, p<0.001$ ) compared to placebo (24\%). Tofacitinib was also found to be superior with respect to the mean change from baseline HAQDI score (5 mg: $-0.39, p<0.001 ; 10 \mathrm{mg}:-0.35, p<0.001)$ compared to placebo $(-0.14)$.

Additionally, both doses of tofacitinib were superior to placebo at three months with respect to ACR50 (5 mg: $30 \%, p=0.003$; $10 \mathrm{mg}: 28 \%, p=0.007$; placebo: $15 \%$ ), but not ACR70 (5 mg: 17\%; $10 \mathrm{mg}$ : 14\%; placebo: $10 \%$ ). With regard to PASI75, the $10 \mathrm{mg}$ dose of tofacitinib was superior to placebo (5 mg: $21 \%$; $10 \mathrm{mg}$ : $43 \%$, $p<0.001$; placebo: $14 \%$ ), but not the $5 \mathrm{mg}$ dose. Prespecified endpoints of resolution of LEI, and improvements in DSS, SF-36, FACIT-F were in the same direction as the primary endpoints but could not be analyzed for statistical significance due to hierarchical statistical testing of secondary endpoints. ${ }^{12,20}$

In OPAL Beyond, the rate of AEs was higher with tofacitinib than placebo at three months (5 mg: $55 \%$, $10 \mathrm{mg}: 53 \%$, placebo: $44 \%$ ). The rates of SAEs were $1 \%$ for tofacitinib $5 \mathrm{mg}, 2 \%$ for $10 \mathrm{mg}$, and $2 \%$ for placebo. The most common AEs were upper respiratory infection, nasopharyngitis, and headache. Four tofacitinib patients reported serious infections (bilateral pyelonephritis, parotitis, pneumonia, and oral candidiasis). Herpes zoster infection occurred in three patients, all of whom were treated with tofacitinib. Two major adverse cardiovascular events (MACE) occurred in patients treated with tofacitinib (myocardial infarction in $5 \mathrm{mg}$ and ischemic stroke in $10 \mathrm{mg}$ ). No deaths or cancers were reported.
Changes from baseline were similar across all groups for hemoglobin and lymphocyte counts at three months. Changes in neutrophil, platelet, creatinine, creatine kinase, and lipid values were observed to be dose dependent. At six months, elevations of AST and ALT greater than the upper limit of normal were observed in patients treated with tofacitinib (AST: 30\%, ALT: 32\%), and elevations three more times the upper limit of normal was also observed in six patients.

OPAL Balance is an ongoing, open-label, long-term extension (LTE) study evaluating the safety and efficacy of tofacitinib in patients with PsA. ${ }^{5,21,22}$ Patients from OPAL Broaden and OPAL Beyond were invited to participate in a three year LTE study within three months of completing or discontinuing the parent study. This study treated 686 patients, who were treated with tofacitinib $5 \mathrm{mg}$ BID or $10 \mathrm{mg}$ BID, depending on treatment response. Primary endpoints were incidents and severity of adverse events and changes in baseline laboratory values. The secondary endpoint was long-term efficacy measured up to month 30 . By month $36,73.2 \%$ of patients reported AEs ( $\mathrm{n}=502), 10.5 \%$ of patients reported SAEs $(\mathrm{n}=72)$, and $2.8 \%$ reported a herpes zoster event $(\mathrm{n}=19)$. MACE was observed in $0.3 \%$ of patients $(\mathrm{n}=2)$ and malignancies were reported in $1.9 \%$ of patients $(n=13)$. Four deaths were reported that were determined to be unrelated to treatment (pancreatic carcinoma, acute cardiac failure, chronic obstructive pulmonary disease, and pulmonary embolism). Four latent tuberculosis adverse events were reported in patients with a previously negative QuantiFERON. Over 36 months of data demonstrated that the safety profile was similar to those reported in previous trials. No new safety risks were reported and efficacy was maintained. 5,22

A 52 week, randomized, double-blind, phase III clinical trial evaluated the safety and efficacy of tofacitinib in Japanese patients with moderate to severe plaque psoriasis $(n=87)$, PsA $(n=12)$, or both $(n=5)$. Patients were randomized $1: 1$ to tofacitinib $5 \mathrm{mg}$ or $10 \mathrm{mg}$ twice daily for 16 weeks, open-label $10 \mathrm{mg}$ twice daily for 4 weeks, then the dose was adjust to tofacitinib $5 \mathrm{mg}$ or $10 \mathrm{mg}$ at the investigator's discretion to 52 weeks. The primary end points were PASI75, Physician's Global Assessment (PGA) of "clear" or "almost clear" for psoriasis, and ACR20 for PsA. At week 16, 62.8\% of patients treated with tofacitinib $5 \mathrm{mg}$ and $72.7 \%$ of patients treated with tofacitinib $10 \mathrm{mg}$ achieved PASI75. The PGA primary end point was achieved by $67.4 \%$ and $68.2 \%$ of patients, 
respectively. ACR20 was achieved by all patients with PsA. The most common AEs were nasopharyngitis and herpes zoster, with $17 \%$ herpes zoster incidence rate. There were no cardiovascular events, deaths, or malignancies reported. ${ }^{23}$

\section{Psoriasis clinical trials}

Multiple, randomized clinical trials have been conducted to evaluate the efficacy, safety, and tolerability of tofacitinib in patients with plaque psoriasis (Table 2).

A phase $2 \mathrm{~b}$ randomized, placebo-controlled, 12-week clinical trial evaluated the efficacy and safety of tofacitinib in patients with moderate-to-severe chronic plaque psoriasis. Patients received $2 \mathrm{mg}, 5 \mathrm{mg}, 15 \mathrm{mg}$ twice daily or placebo. The primary endpoint was the proportion of patients achieving PASI75 at week 12. PASI75 response rates were significantly higher for all tofacitinib groups compared to placebo ( $2 \mathrm{mg}: 25.0 \%, 5 \mathrm{mg}: 40.8 \%$, $15 \mathrm{mg}$ : 66.7\%, placebo: $2.0 \%$ ). Higher response rates for PASI50, PASI90, and PGA were also seen across all tofacitinib groups compared to placebo. This study demonstrated that short-term treatment with tofacitinib could be an effective treatment in patients with moderate-to-severe plaque psoriasis. $^{24,25}$

Two pivotal multi-center, randomized, placebo-controlled, blinded phase III studies, OPT Pivotal 1 and OPT Pivotal 2, were conducted to evaluate the efficacy of $5 \mathrm{mg}$ and $10 \mathrm{mg}$ tofacitinib compared to placebo for patients with moderate-to-severe chronic plaque psoriasis. ${ }^{26-29}$ The two primary endpoints were PASI75 and PGA response at 16 weeks. Both studies achieved the coprimary endpoints, with a significantly greater proportion of patients achieving PASI75 (OPT Pivotal 1: $5 \mathrm{mg}$ : 39.9\%, $10 \mathrm{mg}$ : 59.2\%, placebo: 6.2\%; OPT Pivotal 2: $5 \mathrm{mg}$ : $46.0 \%, 10 \mathrm{mg}$ : 59.6\%, placebo: $11.4 \%$ ) and PGA (OPT Pivotal 1: $5 \mathrm{mg}$ : 41.9\%, $10 \mathrm{mg}$ : 59.2\%, placebo: 9.0\%; OPT Pivotal 2: $5 \mathrm{mg}$, $46.0 \%, 10 \mathrm{mg}: 59.1 \%$, placebo: $10.9 \%$ ) compared to placebo. A dose-dependent improvement was observed with a greater proportion of the tofacitinib $10 \mathrm{mg}$ group achieving PASI75 and PGA response, and in a shorter amount of time, than the tofacitinib $5 \mathrm{mg}$ group. Secondary endpoints of percentage change from baseline of body surface area

Table 2 Summary of key clinical trial results of tofacitinib for the treatment of plaque psoriasis

\begin{tabular}{|c|c|c|c|c|}
\hline Study & Phase & Intervention & PASI 75 & PGA \\
\hline Phase $2 b$ & ॥ & $\begin{array}{l}2 \mathrm{mg} \\
5 \mathrm{mg} \\
10 \mathrm{mg} \\
\text { Placebo }\end{array}$ & $\begin{array}{l}25.0 \% \\
40.8 \% \\
66.7 \% \\
2.0 \%\end{array}$ & $\begin{array}{l}24.5 \% \\
40.8 \% \\
72.9 \% \\
10.0 \%\end{array}$ \\
\hline OPT I & III & $\begin{array}{l}5 \mathrm{mg} \\
10 \mathrm{mg} \\
\text { Placebo }\end{array}$ & $\begin{array}{l}39.9 \% \\
59.2 \% \\
6.2 \%\end{array}$ & $\begin{array}{l}41.9 \% \\
59.2 \% \\
9.0 \%\end{array}$ \\
\hline OPT 2 & III & $\begin{array}{l}5 \mathrm{mg} \\
10 \mathrm{mg} \\
\text { Placebo }\end{array}$ & $\begin{array}{l}46.0 \% \\
59.6 \% \\
11.4 \%\end{array}$ & $\begin{array}{l}46.0 \% \\
59.1 \% \\
10.9 \%\end{array}$ \\
\hline $\begin{array}{l}\text { OPT Retreatment } \\
\text { Withdrawal Period }\end{array}$ & III & $\begin{array}{l}5 \mathrm{mg} \\
10 \mathrm{mg} \\
\text { Placebo } 5 \mathrm{mg} \\
\text { Placebo } 10 \mathrm{mg}\end{array}$ & $\begin{array}{l}56.2 \% \\
62.3 \% \\
23.3 \% \\
26.1 \%\end{array}$ & $\begin{array}{l}49.9 \% \\
63.9 \% \\
22.9 \% \\
18.0 \%\end{array}$ \\
\hline Retreatment Period & & $\begin{array}{l}5 \mathrm{mg} \\
10 \mathrm{mg}\end{array}$ & $\begin{array}{l}36.8 \% \\
61.0 \%\end{array}$ & $\begin{array}{l}44.8 \% \\
57.1 \%\end{array}$ \\
\hline OPT Compare & IIII & $\begin{array}{l}5 \mathrm{mg} \\
10 \mathrm{mg} \\
\text { Etanercept } \\
\text { Placebo }\end{array}$ & $\begin{array}{l}39.5 \% \\
63.6 \% \\
58.8 \% \\
5.6 \%\end{array}$ & $\begin{array}{l}47.1 \% \\
68.2 \% \\
66.3 \% \\
15.0 \%\end{array}$ \\
\hline
\end{tabular}

Notes: Phase 2b and OPT Compare endpoints tested at week 12; OPT I, OPT 2, and OPT Retreatment endpoints tested at week 16; PASI 75, at least 75\% reduction in the Psoriasis Area and Severity Index score; PGA, Physician's Global Assessment; Dosing of etanercept: 50 mg SQ twice weekly; tofacitinib dosed twice daily. 
(BSA), Dermatology Life Quality Index (DLQI), Patient Global Assessment (PtGA), Itch Severity Item (ISI), Nail Psoriasis Severity Index (NAPSI) improvement, and PASI90 were also met.

OPT Retreatment was a randomized, blinded, parallelgroup, phase III trial evaluating the effects of tofacitinib $5 \mathrm{mg}$ and $10 \mathrm{mg}$ withdrawal and re-treatment in patients with plaque psoriasis. The primary efficacy endpoints were the proportion of patients maintaining a PASI75 and PGA response in the withdrawal period, and the proportion of patients achieving a PASI75 and PGA response in the retreatment period, after relapsing in the withdrawal phase. At the end of the withdrawal phase a greater percentage of tofacitinib patients maintained PASI75 (5 mg: $56.2 \%$, $10 \mathrm{mg}$ : $62.3 \%$, placebo $5 \mathrm{mg}: 23.3 \%$, placebo $10 \mathrm{mg}: 26.1 \%$,) and PGA response (5 mg: 49.9\%, $10 \mathrm{mg}$ : $63.9 \%$, placebo $5 \mathrm{mg}$ : $22.9 \%$, placebo $10 \mathrm{mg}$ : $18.0 \%$ ). In the retreatment phase, $36.8 \%$ and $61.0 \%$ of tofacitinib $5 \mathrm{mg}$ and $10 \mathrm{mg}$, respectively, achieved PASI75; and $44.8 \%$ and $57.1 \%$ achieved PGA responses. In sum, this study indicated that tofacitinib could be efficacious after withdrawal and retreatment. ${ }^{30,31}$

OPT Compare was a randomized, placebo-controlled, 12 week, non-inferiority phase III trial comparing tofacitinib $5 \mathrm{mg}$ and $10 \mathrm{mg}$ to high dose entanercept or placebo in patients with moderate-to-severe plaque psoriasis. The primary endpoints were the proportion of patients with a PASI75 and the proportion of patients with a PGA response at 12 weeks of treatment. A PASI75 at week 12 was achieved by $39.5 \%$ of tofacitinib $5 \mathrm{mg}, 63.6 \%$ of tofacitinib $10 \mathrm{mg}, 58.8 \%$ of entanercept, and $5.6 \%$ of placebo. Both tofacitinib and etanercept achieved significant PGA reductions compared to placebo (5 mg: $47.1 \%$, $10 \mathrm{mg}: 68.2 \%$, etanercept: $66.3 \%$, placebo: $15.0 \%$ ). Tofacitinib $10 \mathrm{mg}$ was found to be non-inferior to etanercept, but tofacitinib $5 \mathrm{mg}$ was not shown to be non-inferior to etanercept. ${ }^{32}$

Although study results demonstrated that both the $5 \mathrm{mg}$ and $10 \mathrm{mg}$ doses were effective in treating plaque psoriasis, ${ }^{33-35}$ the $10 \mathrm{mg}$ dose was proven to be more efficacious. ${ }^{36}$ However, this higher dose is associated with increased safety concerns, leading the FDA to decline approval of tofacitinib for moderate-to-severe plaque psoriasis. ${ }^{27,37}$

\section{Safety}

Integrated safety analyses of phase III studies ${ }^{38}$ and the LTE study $^{22}$ found tofacitinib to be well tolerated in patients with psoriatic arthritis with a safety profile that is comparable to other biologics. ${ }^{11,39}$ The adverse events reported in psoriatic arthritis trials were similar to those reported for rheumatoid arthritis and psoriasis. ${ }^{38,39}$

The most common adverse events reported in the phase III trials were upper respiratory infections, nasopharyngitis, and headaches. ${ }^{11,12}$ Tofacitinib has been associated with an increased risk of herpes zoster, which occurred in the active treatment group of both trials. There is also an increased risk of serious infections, including tuberculosis, pneumonia, and influenza.

Due to the immunosuppression induced by tofacitinib, this medication may increase the risk of malignancies. ${ }^{40}$ No cancers were observed in OPAL Beyond, however in Opal Broaden, 4 cancers were reported in patients who received tofacitinib compared to zero patients in the placebo or adalimumab group. Two of the malignancies were reported within 30 days of the first dose of tofacitinib. Furthermore, the three OPAL trials reported adverse cardiovascular events of myocardial infarction and ischemic stroke (Table 3).

Tofacitinib has also been associated with a variety of laboratory abnormalities. Due to the blockade of myelopoietic growth factor signals, ${ }^{3}$ there is an increased risk of cytopenia. Neutropenia and anemia have been observed, but are mild at lower doses. In addition, liver enzyme levels were found to be elevated compared to placebo. Tofacitinib is also associated with a dose-dependent increase in lipid parameters, including total cholesterol, low-density lipoprotein (LDL), high-density lipoprotein (HDL), and triglycerides. ${ }^{41,42}$ In OPAL Beyond, dose dependent changes were also observed in lymphocyte count, platelet count, creatinine, and creatine kinase. For these reasons, routine laboratory monitoring is recommended, and clinicians should follow up on any abnormalities.

The long-term safety of tofacitinib in psoriatic arthritis was evaluated in OPAL Balance. No new safety risks were identified and tofacitinib's safety profile was similar to phase III trials.

\section{Discussion}

Treatment options in PsA have expanded, and choosing among treatments can be a complex decision. Due to the heterogeneous pathogenesis of PsA, patients may not achieve satisfactory disease control with available therapies, which creates a need for alternative treatment options. While TNF- $\alpha$ inhibitors are recommended as first line treatment for active PsA, ${ }^{10,13}$ tofacitinib can 


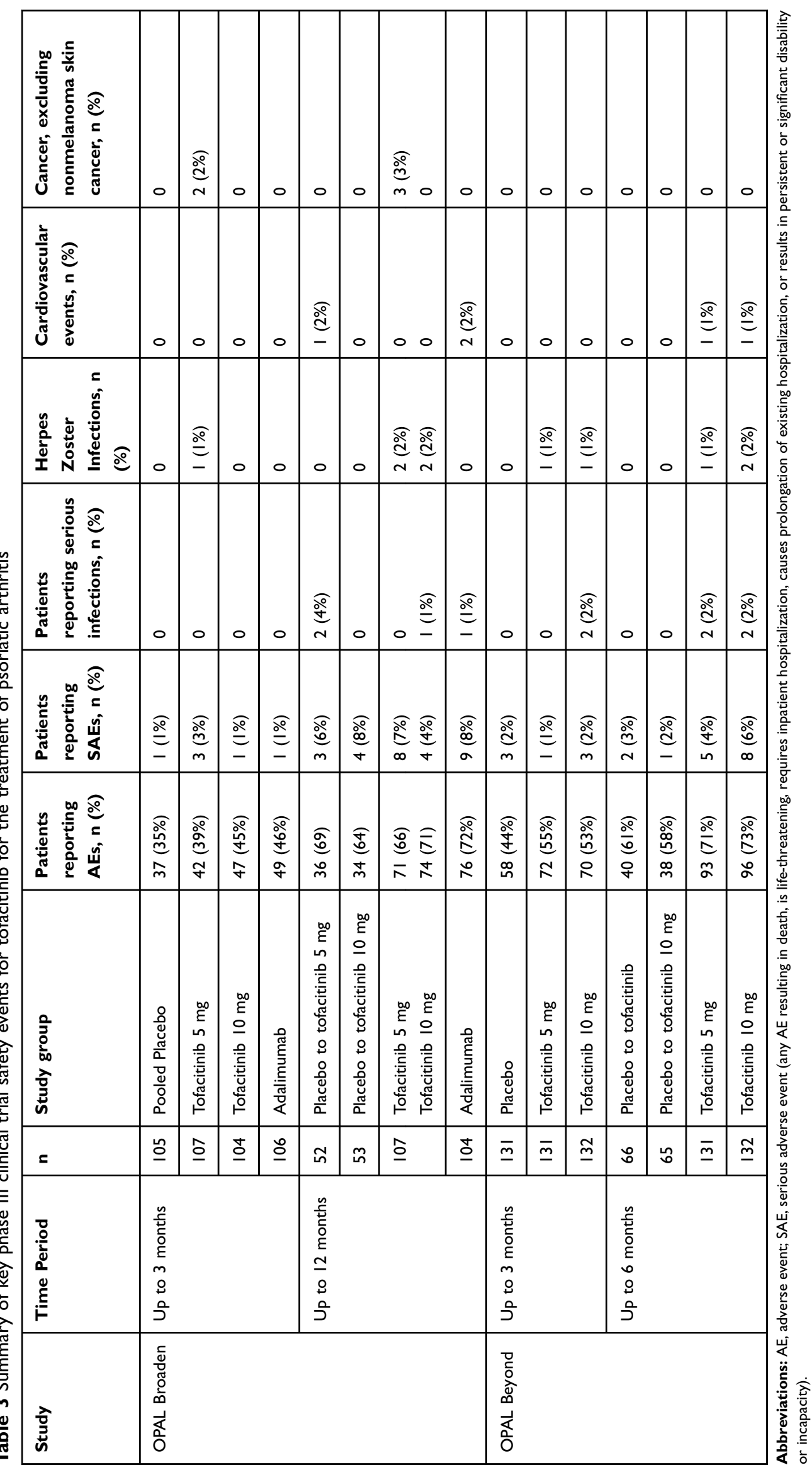


provide an alternative option when injectable biologics are either contraindicated or provide an inadequate response. ${ }^{10}$ Prior to initiating tofacitinib, a thorough assessment of patient preference, disease presentation, and comorbidities is critical.

As an oral medication, tofacitinib provides patients with an alternative to parenteral therapy. Tofacitinib has a similar efficacy profile to biologics, while also offering patients convenience and independence, potentially improving medication compliance and decreasing healthcare costs. Tofacitinib is an alternative to apremilast, an oral phosphodiesterase-4 inhibitor also indicated for psoriatic arthritis. ${ }^{43}$ While apremilast has a favorable safety profile, its efficacy is considerably lower than biologics, ${ }^{44}$ whereas tofacitinib has been demonstrated to have efficacy comparable to biologics.

Tofacitinib can also be considered in patients with difficult to treat disease. The results of OPAL Beyond, which included patients with inadequate response to at least one TNF- $\alpha$ inhibitor, indicate that tofacitinib may be effective in patients with treatment-resistant psoriatic arthritis. In addition, both phase III clinical trials reported improvement in enthesitis and dactylitis, as measured by the LEI and DSS, respectively. These clinical manifestations are associated with an increased burden of disease and decreased quality of life, underscoring the importance of tofacitinib's efficacy in these domains. ${ }^{5,45}$

Furthermore, OPAL Broaden evaluated the effect of tofacitinib on radiographic outcomes and reported that greater than $90 \%$ of patients achieved radiographic nonprogression. ${ }^{11,19}$ The overall rate of radiographic progression was low in all patients.

Although tofacitinib has not received an FDA indication for plaque psoriasis, it has demonstrated efficacy in patients with moderate-to-severe chronic plaque psoriasis in multiple clinical trials, as well as in psoriatic arthritis patients with skin manifestations. Tofacitinib can be considered as a treatment option in patients with psoriatic arthritis and comorbid skin disease. Tofacitinib is also being investigated as a treatment for alopecia areata, vitiligo, atopic dermatitis, and dermatomyositis and may be considered in psoriatic arthritis patients with comorbid disease. $^{46,47}$

There are a number of considerations with regards to tofacitinib's safety profile. There is a black box warning of an increased risk of serious infections and malignancy. Patients should be tested for latent tuberculosis and treated prior to initiation of therapy, and also monitored for signs of serious infection. Patients with chronic, active, or untreated latent hepatitis infections were excluded from tofacitinib clinical trials and thus the risk of chronic viral hepatitis reactivation is unknown. Due to the immunosuppressive effects of tofacitinib therapy, patients should be screened for viral hepatitis in accordance with clinical guidelines prior to initiating therapy. ${ }^{16}$

With regards to the increased risk of malignancy, a pooled analysis from rheumatoid arthritis trials reported that overall rates and types of malignancy remained stable over time with increasing exposure to tofacitinb. ${ }^{48} \mathrm{~A}$ metaanalysis of rheumatoid arthritis trials also reported that the risk of malignancy is similar to nonbiologic and biologic DMARDs, concluding that tofacitinib does not increase rate of malignancies in rheumatoid arthritis. ${ }^{40}$ However, due to these concerns, caution should be exercised in patients with a personal or family history of malignancy. Longer-term studies and registries are needed to evaluate the risk of malignancy in patients taking tofacitinib for psoriatic arthritis.

Furthermore, there was a recent safety alert regarding the risk of pulmonary embolism in rheumatoid arthritis patients treated with tofacitinib $10 \mathrm{mg}$ twice daily. The 36-month OPAL Balance results also reported a death due to pulmonary embolism. Although further data are needed to fully assess this risk, patients should be evaluated for increased risk of a thromboembolic event prior to initiation of therapy. ${ }^{17}$

Tofacitinib is also associated with an increased risk of herpes zoster infection. ${ }^{4-51}$ Risk factors include increased age, Asian race, tofacitinib dose, concomitant steroid therapy, and prior biologic exposure. ${ }^{52}$ The nonlive recombinant zoster vaccine (RZV) is the preferred herpes zoster vaccine for psoriasis and psoriatic arthritis patients. Administration is recommended prior to initiation of therapy but may be safely administered during concurrent tofacitinib treatment. The live-attenuated vaccine (Zostavax) can also be administered but should be given prior the start of therapy. ${ }^{53}$

Laboratory abnormalities are also associated with tofacitinib use, requiring monitoring of lymphocyte, neutrophil, hemoglobin, lipid levels, and LFTs. Since frequent monitoring can be an inconvenience to patients, this should be discussed prior to initiating therapy. Due to the increased risk of cytopenias, tofacitinib should not be initiated in patients with an ALC of less than 500 cells $/ \mathrm{mm}^{3}$, ANC of less than 1000 cells $/ \mathrm{mm}^{3}$, and hemoglobin of less than $9 \mathrm{~g} / \mathrm{dL}$. A pooled analysis of tofacitinib in patients with rheumatoid 
arthritis reported that patients with an ALC less than 500 cells $/ \mathrm{mm}^{3}$ had an increased risk of infection and identified trends towards an increased rate of herpes zoster and opportunistic infections with lower ALC values. ${ }^{54}$ Dosing should be discontinued in patients with an ALC and ANC of less than 500 cells $/ \mathrm{mm}^{3}$. Treatment should be interrupted in patients with a hemoglobin of less than $8 \mathrm{~g} / \mathrm{dL}$ or a decrease of more than $2 \mathrm{~g} / \mathrm{dL} .{ }^{16}$ Compared to placebo, tofacitinib was observed to have a higher incidence of liver enzyme elevations, however, no drug-induced liver injury were reported and incidences of ALT and AST greater than three times the upper limit of normal were rare. Routine monitoring of liver enzymes is recommended and elevations should be investigated.

Of particular concern is the observed increased lipid level, given the association between PsA and cardiovascular disease. ${ }^{55}$ Pooled analysis from OPAL Broaden, Beyond, and Balance reported an increased in LDL and HDL of 9$14 \%$ for tofacitinib $5 \mathrm{mg}$ and $10 \mathrm{mg}$ at three and six months, however no meaningful changes in the ratio of LDL to HDL and total cholesterol to HDL were observed. ${ }^{56}$ Additionally, five patients experienced MACE, of which two were fatal. A pooled analysis reported the risk of MACE in PsA patients treated with tofacitinib to be similar to the general PsA population. ${ }^{56}$ Long-term data is needed to fully understand the cardiovascular risk of tofacitinib treatment and patients with a history significant for cardiovascular disease should be closely evaluated.

\section{Conclusion}

Tofacitinib is an efficacious treatment option for patients with PsA as demonstrated in two placebo-controlled phase III RCTs using the ACR response definitions and the HAQDI. In addition, tofacitinib improved patient reported outcomes and radiographic non-progression in patients with PsA. Tofacitinib therapy, like other biologicals, requires monitoring by the prescribing physician. As an oral therapy, it offers patients an alternative to injectable therapies. The role of tofacitinib in the management of PsA will be elucidated as clinical experience increases and long-term efficacy and safety information become available.

\section{Disclosure}

$\mathrm{KL}, \mathrm{KMB}$, MPS have no conflicts of interest to disclose. AMO is a consultant for Eli Lilly and Company, Novartis, Pfizer and $\mathrm{UCB}$, and has received grant/research support to Johns Hopkins University from AbbVie, Celgene, Eli Lilly and Company, Horizon, Janssen, and Novartis. WL is funded in part by a grant from the National Institutes of Health (U01AI119125) and has received research grant funding from Abbvie, Amgen, Janssen, Novartis, Regeneron, and Sanofi.

\section{References}

1. Ritchlin CT, Krueger JG. New therapies for psoriasis and psoriatic arthritis. Curr Opin Rheumatol. 2016;28(3):204-210. doi:10.1097/ BOR.0000000000000274

2. Singh JA, Guyatt G, Ogdie A, et al. Special article: 2018 American College of Rheumatology/National Psoriasis Foundation Guideline for the Treatment of Psoriatic Arthritis. Arthritis Rheumatol. 2019;71 (1):5-32. doi:10.1002/art.40726

3. Collison J. No increased risk of VTE with tofacitinib. Nat Rev Rheumatol. 2019;15(2):64.

4. Helliwell P, Coates LC, FitzGerald O, et al. Disease-specific composite measures for psoriatic arthritis are highly responsive to a Janus kinase inhibitor treatment that targets multiple domains of disease. Arthritis Res Ther. 2018;20(1):242. doi:10.1186/s13075-018-1739-0

5. Nash P, Coates LC, Fleischmann R, et al. Efficacy of tofacitinib for the treatment of psoriatic arthritis: pooled analysis of two phase 3 studies. Rheumatol Ther. 2018;5(2):567-582. doi:10.1007/s40744-018-0131-5

6. Scher JU, Ogdie A, Merola JF, Ritchlin C. Preventing psoriatic arthritis: focusing on patients with psoriasis at increased risk of transition. Nat Rev Rheumatol. 2019;15(3):153-166. doi:10.1038/ s41584-019-0175-0

7. Raychaudhuri SP, Wilken R, Sukhov AC, Raychaudhuri SK, Maverakis E. Management of psoriatic arthritis: early diagnosis, monitoring of disease severity and cutting edge therapies. $J$ Autoimmun. 2017;76:21-37. doi:10.1016/j.jaut.2016.10.009

8. Ritchlin CT, Colbert RA, Gladman DD .Psoriatic arthritis. $N$ Engl $J$ Med.2017;376:2095-2096. United States. doi:10.1056/NEJMc1704342

9. Bond SJ, Farewell VT, Schentag CT, Gladman DD. Predictors for radiological damage in psoriatic arthritis: results from a single centre. Ann Rheum Dis. 2007;66(3):370-376. doi:10.1136/ard.2006.056457

10. Singh JA, Guyatt G, Ogdie A, et al. Special article: 2018 American College of Rheumatology/National Psoriasis Foundation Guideline for the treatment of psoriatic arthritis. Arthritis Care Res (Hoboken). 2019;71(1):2-29. doi:10.1002/acr.23789

11. Mease P, Hall S, FitzGerald O, et al. Tofacitinib or Adalimumab versus Placebo for Psoriatic arthritis. N Engl J Med. 2017;377 (16):1537-1550. doi:10.1056/NEJMoa1615975

12. Gladman D, Rigby W, Azevedo VF, et al. Tofacitinib for psoriatic arthritis in patients with an inadequate response to TNF inhibitors. $N$ Engl J Med. 2017;377(16):1525-1536. doi:10.1056/NEJMoa1615977

13. Braun J. New targets in psoriatic arthritis. Rheumatology (Oxford). 2016;55(suppl 2):ii30-ii37. doi:10.1093/rheumatology/kew343

14. Virtanen AT, Haikarainen T, Raivola J, Silvennoinen O. Selective JAKinibs: prospects in Inflammatory and Autoimmune diseases. BioDrugs. 2019;33:15-32.

15. Colbert RA, Ward MM. JAK inhibitors taking on psoriatic arthritis. $N$ Engl J Med. 2017;377(16):1582-1584. doi:10.1056/NEJMe1709907

16. XELJANZ (tofacitinib) [package Insert]. New York, NY: Pfizer Inc; 2016.

17. Xeljanz FDA, Xeljanz XR. (Tofacitinib): safety communication safety trial finds increased risk of blood clots in the lungs and death with higher dose in rheumatoid arthritis patients. 2019.

18. Strand V, de Vlam K, Covarrubias-Cobos JA, et al. Tofacitinib or adalimumab versus placebo: patient-reported outcomes from OPAL broaden-a phase III study of active psoriatic arthritis in patients with an inadequate response to conventional synthetic disease-modifying antirheumatic drugs. RMD Open. 2019;5(1):e000806. doi:10.1136/ rmdopen-2018-000806 
19. van der Heijde D, Gladman DD, FitzGerald O, et al. Radiographic progression according to baseline C-reactive protein levels and other risk factors in psoriatic arthritis patients treated with tofacitinib or adalimumab. J Rheumatol.2019;jrheum.180971. doi:10.3899/ jrheum.180971

20. Strand V, de Vlam K, Covarrubias-Cobos JA, et al. Effect of tofacitinib on patient-reported outcomes in patients with active psoriatic arthritis and an inadequate response to tumour necrosis factor inhibitors in the phase III, randomised controlled trial: OPAL beyond. RMD Open. 2019;5(1):e000808. doi:10.1136/rmdopen-2018-000808

21. Costa L, Del Puente A, Peluso R, et al. Small molecule therapy for managing moderate to severe psoriatic arthritis. Expert Opin Pharmacother. 2017;18(15):1557-1567. doi:10.1080/14656566. 2017.1378343

22. Nash PCL, Kivitz AJ, Mease PJ, et al. Safety and efficacy of tofacitinib, an oral janus kinase inhibitor, up to 36 months in patients with active psoriatic arthritis: data from the second interim analysis of OPAL balance, an openlabel, long-term extension study [abstract]. Arthritis Rheumatol. 2017. https://acrabstracts.org/abstract/safety-and-efficacy-of-tofacitinib-anoral-janus-kinase-inhibitor-up-to-36-months-in-patients-with-active-psor iatic-arthritis-data-from-the-second-interim-analysis-of-opal-balance-anopen $\%$ e2\%80\%91/. Accessed, 2019.

23. Asahina A, Etoh T, Igarashi A, et al. Oral tofacitinib efficacy, safety and tolerability in Japanese patients with moderate to severe plaque psoriasis and psoriatic arthritis: a randomized, double-blind, phase 3 study. $J$ Dermatol. 2016;43(8):869-880. doi:10.1111/1346-8138.13258

24. Mamolo C, Harness J, Tan H, Menter A. Tofacitinib (CP-690,550), an oral Janus kinase inhibitor, improves patient-reported outcomes in a phase $2 \mathrm{~b}$, randomized, double-blind, placebo-controlled study in patients with moderate-to-severe psoriasis. $J$ Eur Acad Dermatol Venereol. 2014;28(2):192-203. doi:10.1111/jdv.12081

25. Papp KA, Menter A, Strober B, et al. Efficacy and safety of tofacitinib, an oral Janus kinase inhibitor, in the treatment of psoriasis: a Phase $2 b$ randomized placebo-controlled dose-ranging study. $\mathrm{Br} J$ Dermatol. 2012;167(3):668-677. doi:10.1111/j.1365-2133.2012.11168.x

26. Papp KA, Menter MA, Abe M, et al. Tofacitinib, an oral Janus kinase inhibitor, for the treatment of chronic plaque psoriasis: results from two randomized, placebo-controlled, phase III trials. Br J Dermatol. 2015;173(4):949-961. doi:10.1111/bjd.14018

27. Berekmeri A, Mahmood F, Wittmann M, Helliwell P. Tofacitinib for the treatment of psoriasis and psoriatic arthritis. Expert Rev Clin Immunol. 2018;14(9):719-730. doi:10.1080/1744666X.2018.1512404

28. Feldman SR, Thaci D, Gooderham M, et al. Tofacitinib improves pruritus and health-related quality of life up to 52 weeks: results from 2 randomized phase III trials in patients with moderate to severe plaque psoriasis. J Am Acad Dermatol. 2016;75(6):1162-1170.e1163. doi:10.1016/j.jaad.2016.07.040

29. Papp KA, Krueger JG, Feldman SR, et al. Tofacitinib, an oral Janus kinase inhibitor, for the treatment of chronic plaque psoriasis: longterm efficacy and safety results from 2 randomized phase-III studies and 1 open-label long-term extension study. J Am Acad Dermatol. 2016;74(5):841-850. doi:10.1016/j.jaad.2016.01.013

30. Bissonnette R, Iversen L, Sofen H, et al. Tofacitinib withdrawal and retreatment in moderate-to-severe chronic plaque psoriasis: a randomized controlled trial. $\mathrm{Br} J$ Dermatol. 2015;172(5):1395-1406. doi:10.1111/bjd.13551

31. Griffiths CE, Vender R, Sofen H, et al. Effect of tofacitinib withdrawal and re-treatment on patient-reported outcomes: results from a Phase 3 study in patients with moderate to severe chronic plaque psoriasis. J Eur Acad Dermatol Venereol. 2017;31(2):323-332. doi:10.1111/jdv. 13808

32. Bachelez H, van de Kerkhof PC, Strohal R, et al. Tofacitinib versus etanercept or placebo in moderate-to-severe chronic plaque psoriasis: a phase 3 randomised non-inferiority trial. Lancet. 2015;386 (9993):552-561. doi:10.1016/S0140-6736(14)62113-9
33. Valenzuela F, Korman NJ, Bissonnette R, et al. Tofacitinib in patients with moderate-to-severe chronic plaque psoriasis: long-term safety and efficacy in an open-label extension study. $\mathrm{Br} J$ Dermatol. 2018;179(4):853-862. doi:10.1111/bjd.16798

34. Kuo CM, Tung TH, Wang SH, Chi CC. Efficacy and safety of tofacitinib for moderate-to-severe plaque psoriasis: a systematic review and metaanalysis of randomized controlled trials. J Eur Acad Dermatol Venereol. 2018;32(3):355-362. doi:10.1111/jdv.14695

35. Abe M, Nishigori $\mathrm{C}$, Torii $\mathrm{H}$, et al. Tofacitinib for the treatment of moderate to severe chronic plaque psoriasis in Japanese patients: subgroup analyses from a randomized, placebo-controlled phase 3 trial. J Dermatol. 2017;44(11):1228-1237. doi:10.1111/1346-8138.13956

36. Hutmacher MM, Papp K, Krishnaswami S, et al. Evaluating dosage optimality for tofacitinib, an oral janus kinase inhibitor, in plaque psoriasis, and the influence of body weight. CPT Pharmacometrics Syst Pharmacol. 2017;6(5):322-330. doi:10.1002/psp4.12182

37. FDA declines to expand approval of Pfizer arthritis drug. Reuters. 2015. Pub 2015 Oct 14 .

38. Burmester G, FitzGerald O, Winthrop K et al. Integrated safety summary of tofacitinib in psoriatic arthritis clinical studies. Presented at: Annual European Congress of Rheumatology 2017; 2017; Madrid, Spain.

39. Wang TS, Tsai TF. Tofacitinib in psoriatic arthritis. Immunotherapy. 2017;9(14):1153-1163. doi:10.2217/imt-2017-0087

40. Maneiro JR, Souto A, Gomez-Reino JJ. Risks of malignancies related to tofacitinib and biological drugs in rheumatoid arthritis: systematic review, meta-analysis, and network meta-analysis. Semin Arthritis Rheum. 2017;47(2):149-156. doi:10.1016/j.semarthrit.2017.02.007

41. Wolk R, Armstrong EJ, Hansen PR, et al. Effect of tofacitinib on lipid levels and lipid-related parameters in patients with moderate to severe psoriasis. $J$ Clin Lipidol. 2017;11(5):1243-1256. doi:10.1016/j. jacl.2017.06.012

42. Wu JJ, Strober BE, Hansen PR, et al. Effects of tofacitinib on cardiovascular risk factors and cardiovascular outcomes based on phase III and long-term extension data in patients with plaque psoriasis. $J$ Am Acad Dermatol. 2016;75(5):897-905. doi:10.1016/j.jaad.2016.06.012

43. McAndrew R, Levin E, Koo J. Emerging oral immunomodulators for the treatment of psoriasis: a review of phase iii clinical trials for apremilast and tofacitinib. J Drugs Dermatol. 2015;14(8):786-792.

44. Keating GM. Apremilast: a review in psoriasis and psoriatic arthritis. Drugs. 2017;77(4):459-472. doi:10.1007/s40265-017-0709-1

45. Sondag M, Verhoeven F, Guillot X, Prati C, Wendling D. Efficacy of new treatments for dactylitis of psoriatic arthritis: update of literature review. Clin Rheumatol. 2019;38(2):591-596. doi:10.1007/s10067-018-4328-3

46. Cinats A, Heck E, Robertson L. Janus kinase inhibitors: a review of their emerging applications in dermatology. Skin Therapy Lett. 2018;23(3):5-9.

47. Ciechanowicz P, Rakowska A, Sikora M, Rudnicka L. JAK-inhibitors in dermatology. Current evidence and future applications. $J$ Dermatolog Treat. 2019;30(7):648-658.

48. Curtis JR, Xie F, Yang S, et al. Herpes Zoster in Tofacitinib: risk is further increased with glucocorticoids but not methotrexate. Arthritis Care Res (Hoboken). 2018.

49. Huang F, Luo ZC. Adverse drug events associated with $5 \mathrm{mg}$ versus $10 \mathrm{mg}$ Tofacitinib (Janus kinase inhibitor) twice daily for the treatment of autoimmune diseases: a systematic review and meta-analysis of randomized controlled trials. Clin Rheumatol. 2019;38(2):523534. doi:10.1007/s10067-018-4299-4

50. Noell C, Arbeit R, Kanhoush R. Herpes zoster as a cause of atypical chronic ulcerations associated with tofacitinib. Dermatol Online J. 2018;24(1).

51. Winthrop KL, Lebwohl M, Cohen AD, et al. Herpes zoster in psoriasis patients treated with tofacitinib. J Am Acad Dermatol. 2017;77 (2):302-309. doi:10.1016/j.jaad.2017.03.023

52. Winthrop KL, Curtis JR, Lindsey S, et al. Herpes Zoster and Tofacitinib: clinical outcomes and the risk of concomitant therapy. Arthritis Rheumatol. 2017;69(10):1960-1968. doi:10.1002/art.40189 
53. Baumrin E, Van Voorhees A, Garg A, Feldman SR, Merola JF. A systematic review of herpes zoster incidence and consensus recommendations on vaccination in adult patients on systemic therapy for psoriasis or psoriatic arthritis: from the Medical Board of the National Psoriasis Foundation. J Am Acad Dermatol. 2019;81 (1):102-110. doi:10.1016/j.jaad.2019.03.017

54. van Vollenhoven R, Lee EB, Strengholt S, et al. Evaluation of the short-, mid-, and long-term effects of tofacitinib on lymphocytes in patients with rheumatoid arthritis. Arthritis Rheumatol. 2019;71 (5):685-695. doi:10.1002/art.40780
55. Gladman DD, Ang M, Su L, Tom BD, Schentag CT, Farewell VT. Cardiovascular morbidity in psoriatic arthritis. Ann Rheum Dis. 2009;68(7):1131-1135. doi:10.1136/ard.2008.094839

56. Gladman DD, Charles-Schoeman C, McInnes IB, et al. Changes in lipid levels and incidence of cardiovascular events following tofacitinib treatment in patients with psoriatic arthritis: a pooled analysis across phase 3 and long-term extension studies. Arthritis Care Res (Hoboken). 2019. doi:10.1002/acr.23930

\section{Publish your work in this journal}

Psoriasis: Targets and Therapy is international, peer-reviewed, open access journal focusing on psoriasis, nail psoriasis, psoriatic arthritis and related conditions, identification of therapeutic targets and the

Submit your manuscript here: http://www.dovepress.com/psoriasis-targets-and-therapy-journal optimal use of integrated treatment interventions to achieve improved outcomes and quality of life. Visit http://www.dovepress com/testimonials.php to read real quotes from published authors. 